\title{
A Note on Presentation
}

I have kept the transliteration of Arabic names and terms to a relevant minimum, but where used in the main body of the text, these words have been fully vocalized. When quoting from other sources or citing the titles of Arabic (occasionally Persian) names and books, I have kept the original published transliteration and thus, many will not be standardized to full diacritic marks. Regarding scriptural translations, I have used online translations of the Bible, primarily the New Revised Standard Version via Biblegateway.com. The Qur'ān translations mainly follow Yusuf Ali via quran.com. In both cases, slight modifications have been made for ease of reading where necessary. This includes replacing Allah with God in many passages. 
